\title{
PENGUATAN ORIENTASI KARIR BIDANG OTOMOTIF ANAK DIDIK LEMBAGA PEMBINAAN KHUSUS ANAK
}

\author{
Anastasia Wulandari, Sri Maslihah, Asep Setiadi \\ Departemen Psikologi Fakultas Ilmu Pendidikan Universitas Pendidikan Indonesia \\ e-mail: diangem2_psi@upi.edu,maslihah_psi@upi.edu,asepsetiadihusen@upi.edu
}

\begin{abstract}
This service program is one of life skills education for LPKA students which is expected to be their provision for a career and build economic independence while living a free period and returning to the community (rer-entry). Life skills education provided in the form of vocational training in the field of automotive motorbikes with the aim to improve the career orientation of students of the Special Child Development Institute (LPKA). To test the effect of automotive training on the career orientation of LPKA students, an evaluation of the results of training for LPKA students using the design of one group pretest posttest to 29 LPKA students who will undergo a free period. The evaluation results show the career orientation of LPKA students can be developed through the provision of vocational training in the automotive field, namely the provision of knowledge and skills in pioneering motorcycle entrepreneurship. For future programs, especially related to the provision of vocational training, it is expected to increase the types of skills provided to facilitate the interests of different LPKA students.
\end{abstract}

Keywords :LPKA students, career orientation, vocational training

\begin{abstract}
Abstrak
Program pengabdian ini merupakan salah satu pendidikan kecakapan hidup pada anak didik LPKA yang diharapkan dapat menjadi bekal mereka untuk berkarir dan membangun kemandirian ekonomi saat menjalani masa bebas dan kembali ke masyarakat (rer-entry). Pendidikan kecakapan hidup yang diberikan berupa pelatihan vokasional bidang otomotif sepeda motor dengan tujuan untuk meningkatkan orientasi karir anak didik Lembaga Pembinaan Khusus Anak (LPKA). Untuk menguji pengaruh pelatihan otomotif terhadap orientasi karir anak didik LPKA, dilakukan evaluasi hasil pelatihan pada anak didik LPKA dengan menggunakan desain one grup pretest posttest kepada 29 orang anak didik LPKA yang akan menjalani masa bebas. Hasil evaluasi menunjukkan orientasi karir anak didik LPKA dapat dikembangkan melalui pemberian pelatihan vokasional bidang otomotif, yaitu pemberian pengetahuan dan keterampilan dalam merintis kewirausahaan sepeda motor. Untuk program yang akan datang khususnya terkait pemberian pelatihan vokasional, diharapkan memperbanyak jenis keterampilan yang diberikan untuk memfasilitasi minat anak didik LPKA yang berbeda-beda.
\end{abstract}

Kata kunci : anak didik LPKA, orientasi karir, pelatihan vokasional. 


\section{PENDAHULUAN}

Fenomena anak yang berhadapan dengan hukum dan anak yang berkonflik dengan hukum semakin hari semakin banyak terungkap. Media massa melaporkan telah terjadi berbagai kasus yang melibatkan anak, baik sebagai pelaku, korban, atau sebagai saksi. Masalah anak ini merupakan bagian dari kerawanan sosial yang sering dikaji dan kemudian menjadi dokumen yang berisi rekomendasi bagi pemerintah sebagai pemangku kepentingan yang utama. Namun, kerawanan itu tetap seperti biasa atau bertambah, seolah-olah tidak ada yang berusaha mengatasinya.

Anak yang terbukti melakukan tindak pidana wajib ditempatkan ke dalam Lembaga Pembinaan Khusus Anak (LPKA) yang dulu dikenal sebagai Lapas Anak, sebagai salah satu upaya perlindungan intensif bagi anak dari dampak negatif pemenjaraan saat disatukan dengan penghuni dewasa. LPKA diharapkan lebih ramah bagi tumbuh kembang anak, dengan fokus pada kegiatan pendidikan dan pembinaan. Data dari Direktorat Jendral Pemasyarakatan Kementrian Hukum dan HAM, Anak yang berada di LPKA meningkat sebanyak 90 anak (2.319 menjadi 2.409) dan di LPAS meningkat 180 anak (905 menjadi 1.084) pada tahun 2017 dibandingkan dengan tahun 2016.

Jumlah anak di lapas, rutan, maupun LPKA se-Indonesia menurut Status Pelaporan Klasifikasi Anak Perkanwil per Juni 2017, mencapai 4.081 anak yang berstatus "Anak Pidana". Dari empat ribuan anak tersebut, belum semuanya tertampung di LPKA. Bahkan ada daerah yang belum mencatat keberadaan LPKA di daerahnya. Namun terdapat data yang sangat mencolok, yaitu hampir setengah jumlah anak pidana di Indonesia merupakan anak wilayah Jawa Barat.

Sebagaimana anak-anak pada kelompok usianya, anak yang menjalani pembinaan di LPKA sehubungan tindak pidana yang dilakukannya, mereka berhak memperoleh pembinaan, pembimbingan, pengawasan, pendampingan, pendidikan dan pelatihan, serta hak lain sesuai dengan ketentuan peraturan perundang-undangan. LPKA wajib menyelenggarakan pendidikan, pelatihan keterampilan, pembinaan, dan pemenuhan hak lain sesuai dengan ketentuan peraturan perundang-undangan.

Terkait pendidikan formal bagi anak nara pidana, juga disebutkan bahwa dalam Pasal 4, 5 dan 6 Undang-Undang Nomor 20 tahun 2003 tentang Sistem Pendidikan Nasional (UU Sisdiknas) dapat disimpulkan bahwa anak yang ditempatkan dalam LPKA juga berhak mendapatkan pendidikan tanpa dibeda-bedakan dan pemerintah bertanggung jawab atas penyelenggaraan pendidikan tersebut. Pendidikan yang diberikan pada anak dapat berupa pendidikan formal, informal maupun non formal yang dapat saling melengkapi dan memperkaya. Pendidikan formal terdiri atas pendidikan dasar, pendidikan menengah, dan pendidikan tinggi

LPKA Bandung merupakan LPKA yang dijadikan percontohan untuk sistem pembinaan anak didik LPKA. Di LPKA Bandung, terdapat 40 orang anak didik yang menjalani sekolah setingkat sekolah menengah atas, antara lain 22 anak Sekolah 
Menengah Kejuruan (SMK) dan 18 orang anak Sekolah Menengah Atas (SMA). Sekolah yang menjadi induk proses pendidikan di LPKA Bandung adalah SMK Pekerjaaan Umum Bandung, SMK Pembangunan Pertanian Negeri (PPN) Tanjung Sari dan SMA Langlangbuana Bandung. Selain memenuhi amanat Undang-Undang Sistem Peradilan Pidana Anak (UU SPPA) nomor 11 tahun 2012, penyelenggaraan pendidikan bagi anak didik LPKA, merupakan implementasi dari pemenuhan hak anak dan bagian tidak terpisahkan dari upaya optimalisasi tumbuh kembang anak.

Tujuan dari pembinaan anak didik LPKA adalah untuk memberikan bimbingan kepada anak didik agar menyadari kesalahan, memperbaiki sikap, tidak mengulangi tindak kejahatan lagi sihingga diharapkan dapat diterima kembali dalam masyarakat. Mengacu pendapat Michelle (2013) sebagaimana mantan narapidana, anak didik LPKA akan menghadapi kemungkinan kurang berhasilnya untuk masuk kembali dalam kehidupan bermasyarakat. Hal ini dapat terjadi karena aksebilitas yang rendah dalam bidang pendidikan, pelatihan, dan dukungan moral dari keberadaan keluarga dan kerabat.

Untuk itu perlu dilakukan pembinaan bagi anak didik LPKA yang berorientasi pada peningkatan kecakapan hidup (life skill). Pendidikan kecakapan hidup (life skills) adalah pendidikan yang dapat memberikan bekal pengetahuan, keterampilan yang praktis, terpakai, terkait dengan kebutuhan pasar kerja, peluang usaha dan potensi ekonomi atau industri yang ada di masyarakat (Anwar, 2015). Pendidikan kecakapan hidup (life skills) bagi anak didik LPKA dapat berupa pemberian pelatihan keterampilan sebagai salah satu upaya pemberian bekal pengetahuan dan keterampilan bagi anak didik LPKA agar mereka bisa menjalani kehidupan secara produktif tanpa harus bergantung kepada orang lain. Apalagi pada masyarakat kita masih terjadi stigma negatif terhadap anak yang menjalani pembinaan di LPKA atau Lapas Anak. Melalui pendidikan kecakapan hidup (life skills) mereka dibimbing agar dapat berguna, aktif dan produktif dalam kehidupan masyarakat. Salah satu bentuk pendidikan kecakapan hidup yang dapat diberikan kepada anak didik LPKA adalah melalui pemberian pelatihan untuk meningkatkan keterampilan (vokasional) berupa pelatihan di bidang otomotif yang diharapkan dapat menjadi bekal mereka untuk berkarir dan membangun kemandirian ekonomi saat menjalani masa bebas dan kembali ke masyarakat. Pelatihan vokasional bidang otomotif ini diharapkan dapat mengembangkan orientasi karir anak didik LPKA yang secara psikologis mereka sedang berada pada tahap perkembangan masa remaja dengan salah satu tugas perkembangannya adalah mempersiapkan diri untuk karir di masa yang akan datang. Sebagaimana diungkapkan Havighurst (dalam Hurlock, 2009) bahwa individu yang memasuki usia 13-18 tahun atau usia remaja, memiliki tugas perkembangan, salah satunya yaitu mencapai kepastian untuk mandiri secara ekonomi. Mandiri secara ekonomi artinya memilih pekerjaan dan mempersiapkan diri untuk bekerja. 
Super (1990) menjelaskan bahwa pada masa remaja penting untuk memiliki orientasi karir yang memadai pada diri individu. Orientasi karir yang dimaksud adalah persiapan individu untuk membuat keputusan-keputusan yang tepat tentang karir. Super (1990) menjelaskan tiga dimensi orientasi karir, yaitu: (1) informasi dunia kerja (worldof-work-information), meliputi informasi tentang pekerjaan tertentu dan informasi tentang orang lain dalam dunia kerja. (2) sikap terhadap perkembangan karir (career development attitudes), merupakan arah kecenderungan individu terhadap bidang karir tertentu yang dapat dilihat dari aktivitas-aktivitas yang dilakukan individu yang meliputi perencanaan karir dan eksplorasi karir. (3) keterampilan membuat keputusan karir (skills of career decision making), meliputi penggunaan pengetahuan dalam membuat rencana karir dan penggunaan pemikiran dalam membuat rencana karir.

Pemberian pelatihan bidang otomotif bertujuan mengembangkan orientasi karir anak didik LPKA, yang diberikan melalui tahapan pemberian pengetahuan terkait bidang otomotIf dalam hal ini sepeda motor, yang mencakup pengetahuan tentang perbengkelan sepeda motor dan wirausaha bidang sepeda motor/perbengkelan. Sebagaimana pendapat Munandir (1996) bahwa informasi dunia kerja merupakan segala hal yang berkaitan dengan dunia kerja yang membuat orang menjadi tahu tentang dunia kerja tersebut.

\section{METODE}

\section{Partisipan}

Partisipan dalam penelitian ini adalah 29 orang anak didik LPKA yang akan menjalani masa bebas dalam enam bulan yang akan datang.

\section{Desain}

Untuk menguji pengaruh pelatihan otomotif terhadap orientasi karir anak didik LPKA, dilakukan pengujian evaluasi hasil pelatihan pada anak didik LPKA dengan menggunakan desain one grup pretest posttest kepada 29 orang anak didik LPKA yang akan menjalani masa bebas dalam enam bulan yang akan datang dari pelaksanaan pelatihan. Kelompok tunggal (one group) artinya pengujian dalam penelitian ini dilakukan hanya pada satu kelompok. Pretes-Postes berfungsi untuk mengukur keberhasilan pelatihan yang diberikan. Oleh karena itu, tidak ada kelompok kontrol atau kelompok pembanding yang dijadikan pengukuran.

\section{Asesmen}

Materi pelatihan dibagi pada dua jenis pelatihan, antara lain : 1) Pelatihan Orientasi Karir, yaitu pelatihan dengan materi pengenalan diri, pemberian motivasi dan perencanaan karir. Tujuan pemberian pelatihan ini adalah meningkatkan orientasi karir 
anak didik LPKA untuk bekal kembali ke masyarakat dan keluarga. dan 2) Pelatihan Vokasional, Kewirausahaan dan Perbengkelan Sepeda Motor, yaitu pelatihan dengan memberikan pengetahuan terkait wirausaha perbengkelan sepeda motor.

\section{Prosedur}

Tim pengabdian menyediakan bahan pelatihan orientasi karir dan pelatihan kewirausahaan otomotif sepeda motor yang dilaksanakan dalalm dua bulan (OktoberNovember 2018). Berikut ini skema dari one group pretest and posttes design yang digunakan untuk menguji pelatihan yang diberikan.

Tabel 1

Desain Penelitian One Group Pretest-Postest Design

\begin{tabular}{ccc}
\hline Pretes & Perlakuan & Postes \\
\hline $\mathrm{O} 1$ & $\mathrm{X}$ & $\mathrm{O} 2$ \\
\hline
\end{tabular}

Keterangan:

O1 :Pretes, untuk mengukur orientasi karir sebelum subjek diberi perlakuan

$\mathrm{X} \quad$ :Perlakuan yang diberikan, yaitu Pelatihan Vokasional/Kewirausahaan Otomotif

O2 :Postes, untuk mengukur prestasi belajar setelah subjek diberi pelatihan

\section{HASIL}

Tabel 2

Uji T Orientasi Karir Anak Didik LPKA

Sebelum dan Sesudah Pelatihan Vokasional Otomotif

\begin{tabular}{llrrrrr}
\hline & Mean Std. Deviation & $\begin{array}{c}\text { Std. Error } \\
\text { Mean }\end{array}$ & t & Df & Sig. (2-tailed) \\
\hline Pretes - Postes & $-5,621$ & 4,013 &, 745 & $-7,543$ & 28 &, 000 \\
\hline
\end{tabular}

Hasil analisis data uji beda variabel orientasi masa depan sebelum dan sesudah pemberian pelatihan menunjukkan nilai koefisien beda dengan $t$ sebesar -7,543 dengan p sebesar 0,000 ( $<<0.05$ dan $<0.01$ ) untuk orientasi karir anak didik LPKA artinya, terdapat perbedaan orientasi karir yang signifikan sebelum dan sesudah mengikuti pelatihan orientasi karir dan pelatihan vokasional bidang otomotif pada derajat kepercayaan 95\%.

Bila dilihat data mentah nilai orientasi karir anak didik LPKA setelah dan sebelum mengikuti pelatihan adalah sebagai berikut: 


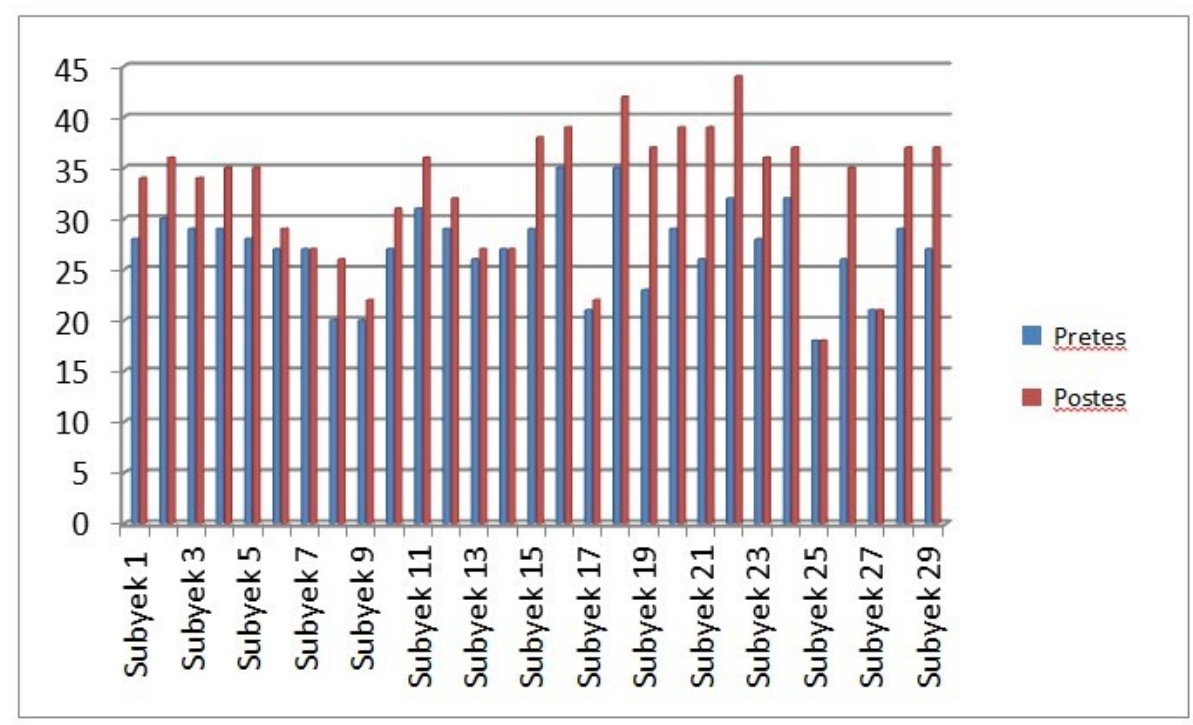

Gambar 1

Gambaran orientasi karir anak didik sebelum dan sesudah pelatihan

Adapun efektivitas pelatihan vokasional bidang otomotif/kewirausahaan sepeda motor adalah sebagai berikut:

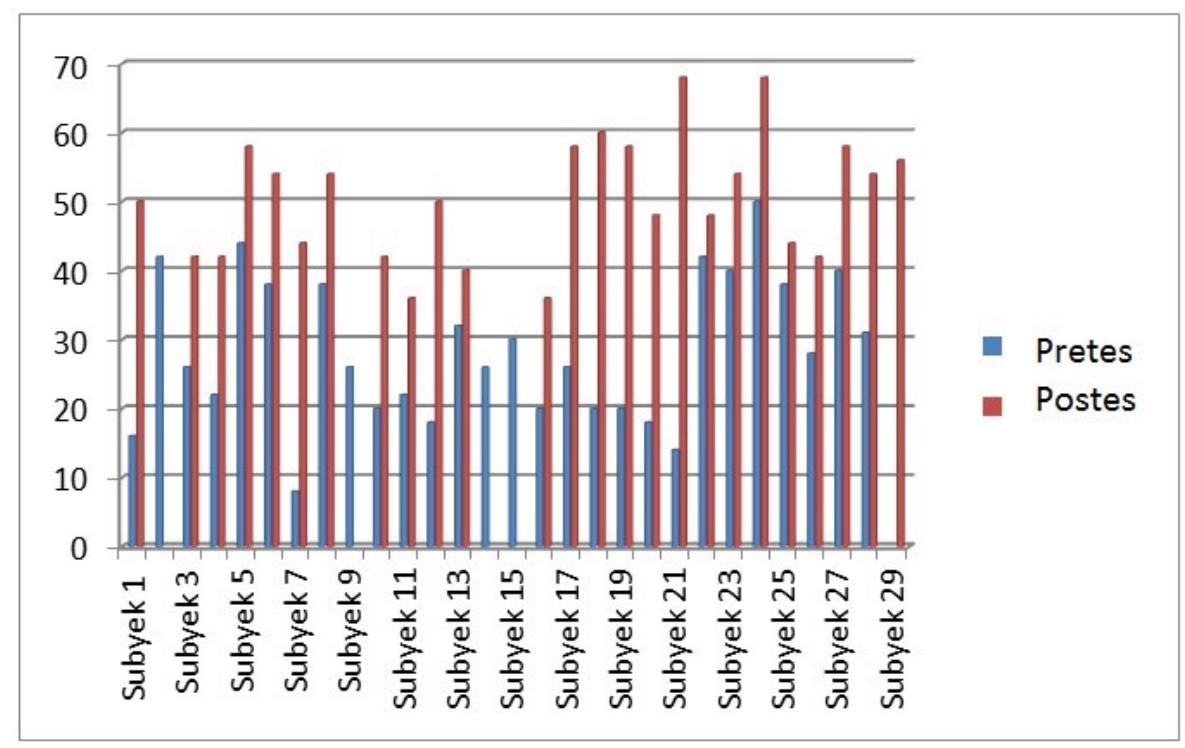

Gambar 2

Gambaran pengetahuan anak didik tentang teknik sepeda motor sebelum dan sesudah pelatihan 


\section{PEMBAHASAN}

Berdasarkan data pada gambar 1 dan gambar 2, meningkatnya orientasi karir anak didik LPKA tidak bisa terlepas dari meningkatnya pengetahuan dan keterampilan anak terkait bidang sepeda motor baik yang berhubungan dengan perbengkelannya maupun dengan kewirausahaannya. Dengan kata lain, penguatan orientasi karir anak didik LPKA tidak hanya ditentukan oleh faktor psikologis dalam diri anak terkait motivasi dan pemahaman karir dan perencanaan masa depan, namun ditentukan juga oleh pengetahuan anak didik LPKA terkait bidang pekerjaan tertentu, dalam hal ini kewirausahaan perbengkelan sepeda motor. Hal ini sejalan dengan pendapat Munandir (1996) bahwa informasi dunia kerja merupakan segala hal yang berkaitan dengan dunia kerja yang membuat orang menjadi tahu tentang dunia kerja tersebut. Sementara menurut Super (dalam Sharf, 1992) informasi dunia kerja (world-of-work-information) mencakup dua konsep utama, yaitu: (1) dimilikinya informasi tentang pekerjaan tertentu, seperti informasi tentang jenis-jenis pekerjaan yang sesuai dengan karir yang diharapkan, cara memasuki dunia kerja atau informasi berkaitan tentang adanya aturan dalam pekerjaan tertentu. (2) dimilikinya informasi tentang orang lain dalam dunia kerjanya, seperti bagaimana orang lain mempelajari tentang pekerjaannya atau bagaimana orang berhasil dalam berkarir.

Pemberian pelatihan otomotif memberikan kontribusi positif bagi anak didik LPKA sehingga mereka memiliki gambaran tentang pekerjaan pada bidang teknik sepeda motor. Hal ini diharapkan menjadi bekal bagi anak didik LPKA yang akan menjalani masa bebas dan tidak melanjutkan sekolah formal ataupun telah menyelesaikan pendidikan formal setingkat SMK dan tidak melanjutkan kuliah.

Orientasi karir anak didik Lembaga Pembinaan Khusus Anak (LPKA) dapat dikembangkan melalui pemberian pelatihan vokasional bidang otomotif, yaitu pemberian pengetahuan dan keterampilan dalam merintis kewirausahaan sepeda motor. Sebagaimana hasil penelitian ini yang menunjukkan terdapat pengaruh positif pemberian pelatihan vokasional terhadap penguatan orientasi karir anak didik LPKA. Melalui pelatihan ini anak didik LPKA mendapatkan informasi dunia kerja kewirausahaan sepeda motor baik yang berhubungan dengan perbengkelannya maupun dengan kewirausahaannya.

\section{DAFTAR PUSTAKA}

Anwar. 2015. Pendidikan Kecakapan Hidup (Life Skill education). Bandung : Alfabeta Hurlock, E. (2009). Psikologi Perkembangan. Jakarta: Erlangga 
Michelle, A. 2013, A. Second Chance: Charting a New Course for Re entri Criminal Justice Reform. The Leadership Conference Education Fund.

Munandir. 1996. Program Bimbingan Karir di Sekolah. Jakarta: Ditjen Dikti

Sharf, Ri.S. 1992. Applying Career Development Theory to Counseling. California:Brooks/Cole Publishing Company

Super, D.E. (1990). A-Life-span, life-space approach to career development. Dalam D.Brown, L.Brooks \& Assoc. Career Choice and Development ; Applying Contemporary Theories to Practice. San Francisco:Jossey-Bass

Undang-Undang Nomor 20 tahun 2003 tentang Sistem Pendidikan Nasional;

Undang-Undang Nomor 11 Tahun 2012 tentang Sistem Peradilan Pidana Anak; 